\title{
Hombre y religiosidad desde Manuel Gonzalo Casas
}

\author{
Man and Religiosity from Manuel Gonzalo Casas
}

Homem e religiosidade desde Manuel Gonzalo Casas

Prof. Carla S. Prado*

\section{RESUMEN}

El artículo aborda la manera particular en que el pensamiento religioso condiciona la existencia del hombre en el mundo desde el análisis de Manuel Gonzalo Casas, quien utiliza este registro para interpretar la mundaneidad en relación a la trascendencia, no solo desde su obra filosófica sino también desde su literatura. Lo que se juega en esta relación resulta fundamental a la hora de pensar cómo el género humano se vincula entre sí a través de esta religio. En este sentido, analizaremos la obra del autor para registrar los momentos de mayor tensión, que nos permitirán seguir pensando acerca de cómo nos relacionamos a partir de este condicionamiento.

\begin{abstract}
This article addresses the particular way in which religious thought conditions the existence of many in the world, from the analysis of Manuel Gonzalo Casas, who uses this register to interpret the mundane in relation to transcendence, not only in his philosophical work but also in his literature. What is at play in this relationship is fundamental when thinking about how the human race is tied together through this religio. In this sense, we will analyze the author's work to record moments of greater
\end{abstract}

Palabras clave: Manuel Gonzalo Casas, existencia, religión, mundaneidad, trascendencia,

Keywords:

Manuel Gonzalo

Casas, existence, religion, mundane, transcendence

Argentina. Profesora de Grado Universitario en Filosofía por la Facultad de Filosofía y Letras de la Universidad Nacional de Cuyo, Mendoza, Argentina. Forma parte del Instituto de Filosofía Argentina y Americana (FFyL, UNCuyo). Contacto: carlaspradoa@gmail.com

ORCID: https://orcid.org/0000-0001-7438-0147 
tension, where we continue to think about how we relate to each other based on this conditioning.

\section{RESUMO}

$\mathrm{O}$ artigo aborda a maneira particular com que o pensamento

Palavras-

chave: Manuel

Gonzalo Casas, existência, religião, mundaneidade, transcendência literatura. O que está em jogo nesta relação resulta fundamental na hora de pensar como o gênero humano se vincula entre si através desta religio. Neste sentido, analisaremos a obra do autor para registrar os momentos de maior tensão, que nos permitirão continuar pensando sobre como nos relacionamos a partir deste condicionamento. 


\section{Introducción}

Manuel Gonzalo Casas (1911-1981), oriundo de la Ciudad de Córdoba, Argentina, se desempeñó durante algunos años como profesor en la Universidad Nacional de Cuyo, en Mendoza, lugar donde se encuentra su archivo y desde el cual nos proponemos una lectura sobre su visión acerca de la existencia del hombre, la cual conjuga de manera muy particular cuestiones de la religiosidad (desde una formación tomista) con cuestiones materialistas, brindándonos un espectro amplio para repensar la cuestión de la existencia del hombre y su ser-con-otros. Esta articulación es problemática, en tanto el existir en cuanto tal se encuentra en un 'ahí' cuya condición está afectada por/a través del religo y es esta vinculación, según la plantea el autor, la que pretendemos explorar.

Casas tiene una particularidad: sus registros de escritura dan cuenta de un autor polifacético que, más allá de dictar clases y seminarios, fue escritor de una literatura de profunda densidad conceptual, como es el caso de El Laberinto, Cuento nivolado en varios sueños y dos pequeñas vigilias. Este da cuenta de un recorrido por la existencia, en la que se van articulando las condiciones materiales con la propia fe, a la par de un amor terrenal que pone en jaque la posibilidad amatoria del creyente que busca, en el bajo fondo de toda palabra, una trascendencia que lo lleve hasta el absoluto.

Para comprenderla mejor, esta obra será observada en sí misma y también a la luz de la Introducción al pensamiento real (1979) (una serie de conferencias dictadas en Mendoza), dado que ambos textos articulan una preocupación por el fin del accionar humano, no solo en función de la propia individualidad sino en el punto convergente de la humanidad toda. Tanto desde la novela filosófica como desde el contenido de este seminario, podemos recuperar claves para el cuestionamiento de nuestro estar en el mundo.

Estas claves van a aparecer también en el tratamiento, por otro lado, de su Introducción a la Filosofía (1967), la cual surge de una recopilación de las clases dictadas por él en la Universidad Nacional de Tucumán, entre 1952 y 1953. Aun cuando estas no son sus únicas obras publicadas, nos parecen las bases para comenzar a conocer a este autor que, a pesar de su gran trayectoria escritural y docente, no ha sido 
debidamente reconocido hasta ahora en la historia de las ideas latinoamericanas. Es este otro de los motivos que nos llevan a analizarlo, para dejar registro de otra forma posible de entender la convivencia humana a través de comprender la vinculación entre religiosidad y humanidad.

Es menester reparar en que la metodología de trabajo en esta Introducción que mencionábamos es, por momentos, historiográfica, pero que responde también a un desarrollo de ideas que lo hacen ir y venir en el tiempo. En este sentido, asimilaremos este modo del devenir metodológico. El mismo nos parece eficaz a la hora de repensar los acontecimientos, reincorporando sucesos pasados que están en juego para entender las situaciones que el autor delimita. Todo eso será nuestra materia prima para repensar su eco en la actualidad y cómo esta vacilación por el ser del hombre y su relación entre sí, que vemos nuevamente aflorada por reivindicaciones de igualdad, necesita de una revisión de las condiciones de nuestro religo. En este sentido, nuestro objetivo de investigación es establecer un modo posible de entender la problematicidad de esta vinculación en la obra seleccionada de Manuel Gonzalo Casas.

\section{Una mirada a partir del Renacimiento}

Entrecruzando su mencionada Introducción a la filosofía con un trabajo menor, titulado "El humanismo como formación del hombre", encontramos un punto en el cual Manuel Gonzalo Casas establece una conexión epocal en el Renacimiento, a saber: el humanismo, comprendido en tanto acceso al ser mismo del hombre.

Aun cuando el autor se sitúa a sí mismo en una posición compleja al hablar de la época renacentista, advierte que esto no se debe a una escasez de material acerca de ésta, sino, por el contrario, a la vasta proliferación intelectual y artística que se da entre los siglos XV y XVI. Aun así, no se detiene inicialmente en el estudio de esta época, sino que se remonta a rastros medievales que nos sirven para llegar a la formatio hominis que lo caracteriza.

El griego da por supuesto, en general, que el mundo y las cosas existen y lo que trata de saber es lo que son. Por eso, la idea de una eterna presencia, o retorno del mundo, es fundamental para los griegos. 
Pero, para el cristianismo, la cosa es más grave. El cristianismo no se asombra sólo por el qué, por las esencias, por los constitutivos de la realidad. Al cristianismo lo asombra el hecho mismo de que haya una realidad: lo asombra la existencia de la realidad (Casas 1967 23).

Y una existencia de la realidad en relación con la finitud y el padecimiento humanos, circunstancias que aparecen como claves de lectura que el autor nos brinda, para analizar de qué se trata la relación entre humanismo y Renacimiento. Casas se posiciona desde esta relación conceptual para abordar la época. Lo cual, a su vez, habilita para él el comienzo de la fisura medieval a partir la posición de Tomás de Aquino respecto del conocimiento.

En su distinción entre filosofía y teología, como diferencia entre saber racional y saber de fe, aquella primera se alza - según la metodología de vaivén que utiliza Casas para recorrer las ideas- siguiendo una línea aristotélica: como ciencia de las últimas causas a partir del desarrollo natural de la inteligencia. En su sentido tomista, la verdad acaba siendo divina, habiendo un ultimátum dado por la fe cristiana. Sin embargo, la inteligencia, pensada como algo desarrollable y actualizable, puede ser proyectada en tanto puerta que queda abierta a la modernidad. En este sentido, Francisco Suárez es la coronación de la tradición medieval, aunque se encuentre por fuera de ella, ya que constituye el tratamiento del ser en cuanto ser, diferenciado de la teología natural como ser de dios.

Con esta diferenciación se inaugura un conocimiento del hombre que busca abrirse a la experiencia del clásico como quien ha encarnado la realidad en el logos, siendo ella en sí inaprensible pero pasible de expresarse a través del hombre. Así se va constituyendo la figura humana como eje central del movimiento histórico, lo que permite hablar del renacimiento tan ligado al humanismo. Toda formación humana, para Casas, debe realizarse a través de las expresiones del ser de hombre. Esto es lo que nos permite articular la noción de "hombre" con la noción de "religión", dado que parte del humanismo debe dar cuenta de esta ligazón fundamental, que Casas hace patente en su relación con lo absoluto que es dios.

Es entonces que, como mencionábamos, una de las experiencias fundamentales que subyacen a cualquier expresión que derive en sa- 
ber humano es la finitud, la cual se manifiesta como tal bajo la forma de "padecimiento". Y no solamente como propuesta teórica sino en la situación cotidiana en que la realidad impone su límite. Es en este "enfrentamiento" con las cosas que el hombre se descubre a sí mismo y, en tanto a sí, a lo que otro que le rodea. La existencia a sabiendas de la muerte es una muestra de esta finitud sustantiva. Sin embargo, para el autor, esta propia limitación es signo también de una otredad mayor, que engloba incluso aquello que nosotros mismos entendemos como otro: allí donde desaparece toda diferencia bajo la forma de la "trascendencia".

A través de la palabra vuelta obra, del poetizar elemental a la base de todo lenguaje, el hombre libera una expresión que viene desde su raíz y experimenta un cierto grado de emancipación: el hombre expresa su situación de forma significativa y, en ese señalarse, señala lo otro de sí en referencia a él y lo posee nombrándolo. Aquí está el sentido profundo del humanismo en relación con el Renacimiento: no interesan fundamentalmente las cosas en sí sino en cuanto expresan al hombre. Esto no solo genera modificaciones en la estética sino también en la metafísica. Hay un nuevo sentido de la historia, en el que las huellas pasadas del hombre se tornan objeto de culto, como es el caso del mundo clásico y su recuperación. Como expone más adelante en su introducción:

Refiriéndonos a los modos de realización de la vida humana, no solo estar con y entre las cosas que pueblan mi contorno, sino algo más: supone un trato con esas cosas; una ocupación con esas cosas y con el mundo en que las cosas y el hombre mismo se encuentran. Aclaramos: no se trata de concebir un hombre y concebir un mundo y luego establecer o tender un puente entre ambos. El estatuto mismo en que el hombre se funda es la copresencia de una realidad abierta y en contacto con su ser. Y el ocuparse con el mundo tampoco es optativo; no hay alternativa; ser hombre es ocuparse con eso: con la realidad presente del mundo - aunque fuera incluso para negarla. (Casas 1967 54).

En el fondo de la propia existencia, en esta "ocupación", aflora una necesidad de expresión realizada solo por el hombre, donde la capacidad racional comienza a mostrarse como potencial característica de la condición humana. Estas expresiones son, a su vez, movilizadas por 
todo aquello otro que no es el sujeto, o que determina el terreno del ser hombre para reconocerse limitado. Allí, en la multiplicidad de posibles manifestaciones de la expresión, hay una instancia metafísica en la cual -incluso de manera implícita - sabemos que no lo podemos todo. "Expresión" viene a ser justamente esa presión que busca salir desde dentro, y es signo de la relación con la realidad circundante. Su problema es que se da junto a la pregunta por el ser, en ese abismo y ese vértigo frente a la finitud que nos moviliza a buscar la trascendencia. El legajo artístico que se deja, en el amplio espectro que pueden significar "las artes", es también una forma de vencer al tiempo, de dejar un rastro de existencia. Poder usar ese mundo en el que se está y estar en un mundo son las articulaciones que se dan en la expresión emergente, que se enmarca a su vez en una fuerte impronta de lo humano como hacedor, como faber.

Para Casas, no puede haber humanismo sin metafísica, porque todo humanismo consciente de sus propios supuestos hace uso de una hermenéutica que interpreta y da sentido para hacer posible el acceso a las expresiones humanas, siendo que todas estas revelan la emergencia del contacto con algo 'otro' en los márgenes de una vida finita. En este sentido, incluso la ciencia - en su intento objetivo- revela una instancia de contacto con el ser. Lo cual no quiere decir que este pase a ser el eje principal de su discurso, pero sí está contemplado inevitablemente. Desde ahí es que también hay una referencia particular a "la palabra" en la formatio hominis renacentista, ya que expresa la experiencia metafísica fundamental como padecer originario, en tanto se asocia, tradicionalmente, con la luz. Esta asociación la podemos clarificar si tenemos en cuenta su formación y lo que ha significado históricamente esta figura (junto a la del verbo) en una lectura religiosa cristiana. "Palabra" se usa íntimamente ligada a la noción de inteligibilidad, y el hombre vendría a ser, manteniendo este sentido, el logos de la tierra, desde el cual y en el cual aparece la experiencia como organizadora del mundo. La grandeza del hombre radica en su capacidad creadora, que podríamos pensar incluso en reacción al estadio medieval previo. Ya no solo es dios quien crea, sino que el hombre actualiza esta pequeña potencia divina para sí: se trata de crear un mundo-acá.

En este sentido, el Renacimiento no se trata de una inauguración aislada en la historia, sino que carga en su propio seno los vestigios 
clásicos y medievales: hubo ya algo. La formación humanista del hombre se da en base a lo ya existente. De hecho, la recuperación de un pasado anterior como referencia a lo humano se asocia a este modo de conocer y de interpretar el mundo y sus vínculos, ya que se busca en ello algo digno de ser recuperado, una reinterpretación de la pregunta por las cosas, ya no tanto en clave ontológica sino como manifestación del propio ser del hombre en su expresión.

Casas, viendo en Pico Della Mirandola y su Discurso sobre la dignidad del hombre la más alta expresión del humanismo renacentista, se anima a decir que, desde entonces hasta el existencialismo inclusive, habiendo pasado por Hegel, Nietzsche y el marxismo, la tarea del pensar será hacer el hombre. Poco a poco la figura del sujeto comienza a emerger, a la vez que la esencia humana se pluraliza: hay un doble movimiento de fijación y conquista, de descubrir-se sujeto al encontrar a "otros", quienes pareciera que, con su propia existencia, reclaman también esa categoría. Sin pretender creer que recién entonces el hombre cae en el reconocimiento de una otredad más allá de sí, es interesante pensar que el relato del religo va mutando, imbricado siempre a las nociones de "hombre", "sujeto" y "humanidad", dado que se trata justamente de actualizar el vínculo entre esas subjetividades mundanas que van, a su vez, descubriendo el mundo.

Desde Pico Della Mirandola podemos decir al hombre como un milagro en su plasticidad de hacerse a sí mismo. Y esta suerte de capacidad creativa y creadora es la que transforma lo humano en algo maravilloso, partícipe de lo divino. Sin embargo, la divinidad medieval se debilita en tanto crece esta facultad de hacer del hombre. En sí, no es que debilite el concepto de "dios", que sigue vigente hasta nuestros días, pero sí se nota un cambio en la actitud del hombre que se va configurando moderno. Lo que antes era la luz como símbolo de conocimiento, de bondad, de trascendencia, se torna fenómeno natural pasible de ser estudiado, de ser utilizado como técnica — por ejemplo- en la pintura.

En la recuperación de lo clásico, la téjne es nuevamente una pregunta que se responde en la poiesis. Y cabe tener presente que no significa que estos aspectos hayan sido olvidados por completo durante el periodo previo, pero sí que la relevancia que les corresponde es distinta. En el renacimiento vuelven a configurarse los estándares clásicos de 
la mesura griega, con nuevas técnicas, con nuevos lienzos, con nuevos lenguajes. $\mathrm{Y}$ es el hombre quien se pone al hombro este nuevo mundo, del cual él mismo es su creador. Pero no solo crea "mundo" sino también otros hombres, y allí radica lo fundamental del humanismo: la formatio hominis, atravesada transversalmente por la finitud y el padecimiento humano que la llevan a cabo.

\section{El salto moderno}

Mirar hacia "la modernidad" entendiéndola culminada es, en alguna medida, sentirse lo suficientemente lejos como para nombrarla pasada o, al menos, ajena. Es arduo el ejercicio que implica tratar de entenderla en sus términos y, sin embargo, encontramos fundamental explorar qué de ella mantiene aún su existencia a través del cauce temporal del siglo XX. Si nuevamente recurrimos a la Introducción a la Filosofía de Casas, encontramos que el sujeto como tal fue y sigue siendo una poderosa configuración que emergió y se hizo fuerte, al menos al comienzo, en su cogito moderno. Sin embargo, antes de meternos de lleno en el tratamiento de este, quisiéramos traer a colación a Descartes - aunado a Husserl-, tal como lo hace esta Introducción, a saber: en una mención a la fenomenología, en tanto precursor de la conciencia. Con la duda metódica cartesiana se inaugura una desconfianza al recorrido epistemológico medieval y se establece un saber de sí como evidencia apodíctica: la res cogitans. Esta forma de "confirmar" la existencia mantiene, sin embargo, un enclave que podríamos identificar como cristiano respecto de la distinción cuerpo y alma. De esta manera, la incipiente modernidad comienza con un pie en su antecesora: aunque opositora del dogmatismo religioso, conserva en su despliegue la servidumbre a esta dicotomía. Si bien Casas no ignora la existencia de Spinoza en su unidad, mencionándolo en esta introducción cinco veces y definiéndolo como la "máxima tensión del racionalismo", la noción de modernidad pasa a jugarse para él en la categoría de "subjetivismo religioso".

El yo, para Descartes, es, en realidad, un trampolín que me reenvía hacia la trascendencia por la imperfección y la finitud; la conciencia de Husserl es una corriente de vivencias y esas vivencias son siempre líneas intencionales que unen a un sujeto con un objeto (Casas 1967 263). 
Aquello que comienza separando al sujeto del mundo, a través del solipsismo, y que va a establecerse como conocimiento fenoménico en su veta kantiana, culmina en el espíritu absoluto de Hegel según el camino que traza esta Introducción. Por ende, allí donde no hay más sistema, más idea de totalidad absoluta, no hay modernidad. Aquel sujeto que pudo declararse a sí mismo "conocedor" es reencontrado a través de su propio recorrido como conocido: hay una unidad fundamental que lo une, que lo liga, que lo religa en lo absoluto. El binomio sujeto-objeto se supera en una síntesis que, a pesar de su profundidad conceptual, no deja de parecer, en última instancia, un soplo. Y Casas, aunque no dedique un capítulo particular a Hegel, abre el espacio de su explicación en un capítulo titulado: "El marxismo".

Anunciándola como la última lección, no tiene mejor manera de comenzarla que advirtiendo una carga de significaciones y esquemas de origen religioso, que le otorga cierta potencia mesiánica. "La realidad", que para Hegel había sido un proceso dialéctico de negaciones cuyo fundamento era la idea, para Marx lo era en base a la materia, que en el hombre concreto resultan ser sus necesidades materiales. Se expone allí una idea procesual de la historia, en la cual estas necesidades se satisfacen mediante el trabajo, como "evolución" del estado de indigencia. Sin embargo, el quiebre que se genera en este proceso homogéneo y autónomo, a través del comercio y la propiedad privada, hace que el opus, en tanto síntesis expropiada, enajene al hombre creador y, por ende, al trabajo. En este sentido, se establece históricamente un despliegue que supera la relación dueño-esclavo en pos del Estado feudal. Luego, la superación del estadio señor y ciervo hacia el Estado Burgués, y allí el establecimiento entre burguesía y proletariado.

Cada una de estas formas de organización "cura" la enajenación particular anterior, es decir, la supera, pero en última instancia es el socialismo el que va a "curar" la enajenación en cuanto tal. Aquí se da la transposición del supuesto orden ideal al material, aquella "vuelta al estado de naturaleza" u originario. Sin embargo, hay una pregunta en la cual, según el autor, cabe detenerse: ¿tiene sentido objetar el proceso de la historia de Marx? Si fuese fundamentalmente dialéctico sí, pero es fundamentalmente mesiánico.

En esta nueva sensibilidad por los problemas sociales y la condición humana también se halla un registro religioso, casi como ger- 
men genético. Entonces, ¿cuál es el recorrido que está transitando ese "hombre" desde la Grecia clásica hasta una Europa próxima, en tanto humanidad? A cuya pregunta en este recorrido, teniendo en cuenta la cesura de la metafísica en tanto límite de lo que no podemos conocer (con Kant como epicentro), sigue otra: ies abandonado desde entonces el temor metodológico de nombrar a dios como fundamento último, no como nombre sino en tanto contenido categorial? Esta pregunta remite directamente al propósito de esta investigación, ya que se trata de dilucidar cómo el vínculo entre religiosidad y humanidad moldea o constituye formas de estar en el mundo con otros.

Casas, quien fue uno de los pocos que se animaba a dictar - cuando profesor de la Universidad Nacional de Cuyo- clases sobre Marx (según una entrevista realizada a Margarita Guerrero en el marco del proyecto de investigación Filosofía y Educación en Mendoza en el S. XX, 30/05/2018), rescata, llegando al final de este último capítulo, una visión de la verdad ya no como alétheia, como corrimiento del velo, sino como acto, como praxis política. Es esto lo que le permite recuperar con mayor fuerza la "religión". Aun cuando esta trata de ser planteada, según la interpretación del autor respecto del marxismo, como un escape ideológico (tanto como la idea de moral y de estado), él retoma su sentido etimológico en función de pensar esa praxis.

Una modernidad comenzada por el solipsismo, como decíamos más arriba, ¿qué punto de encuentro establece? Aquella o aquellas figuras que convocaron a la especie humana, no solo en las narraciones cristianas sino en las de diversos pueblos originarios, ¿dónde quedan guardadas, más que en enciclopedias? La pregunta no es por un dios nunca olvidado por la tradición judeocristiana, utilizado muchas veces cual comodín cuando el cuestionamiento acorrala, sino en tanto re-ligo. El subjetivismo religioso que reclama Casas a la modernidad parece tener la clave de no perder, en definitiva, un trasfondo inexplicable, un acto de fe, así sea respecto de la mejora de las condiciones materiales a través de la lucha, de la abolición de la propiedad privada u otras.

Una filosofía que se esmeró por ser ciencia, una ciencia aparentemente despojada de estas incoherencias, de estos supuestos invisibles sin constatación empírica, ¿no guarda, en el fondo, la esperanza de una noción de verdad que nos involucre en un mundo? "Ascéticos" nos dirá 
Nietzsche (2005) más adelante, más cerca nuestro y, sin embargo, todavía indescifrable por completo. Sin embargo, sin necesidad de que sea pura ni a priori, cabe pensar qué nos posibilita la vuelta sobre la modernidad a la hora de pensar este espacio de encuentro, no necesariamente como institución de dioses sino más bien como rituales que utilizamos para mantenernos en contacto, y no solo como esperanza de futuro sino también como forma de llevar diariamente a cabo nuestra existencia.

La coaptación del sentido profundo del religo bajo determinadas formas institucionales, con determinados parámetros preestablecidos de divinidad posible, puede empañarnos el lente a la hora de ver cómo aquel sujeto no terminó, aunque hubiese querido, de estar solo en ese mundo del sí mismo, en su propia conciencia, en su propio lenguaje. Como no terminó nunca de aislarse en el laboratorio, ni ser estrictamente experimental para sí, como tampoco se unió al todo plenamente, ni se consumó en vida (o muerte), ni pudo prescindir por completo del pan de cada día. Esta Introducción a la Filosofía, surgida entre 1952 y 1953, pero publicada en su primera edición por Gredos en 1959, cerraba con el marxismo. Sin embargo, no bastó con eso. En 1967 incorpora la filosofía del Yo-Tú. Y para esa filosofía de inspiración buberiana:

No se trata, nunca, de salir a probar la existencia de Dios. Dios aparece como el supuesto fundamental, desde el cual es posible toda partida, tan pronto analizamos los contenidos y las exigencias intrínsecas a la relación misma. La 'religio', el 'religamiento', como conditio sine qua non, resulta entonces un auténtico concomitante existencial, una realidad constitutiva que abre el horizonte de mi prospección y la ilumina desde su raíz (Casas 1967 339).

Es interesante pensar las instancias de ligamento como dispositivos, apoyando los pies en el suelo de nuestra época, no en tanto "meros" dispositivos sino como construcciones históricas que vienen de la modernidad, ya con todo su bagaje anterior, y que siguen activas en nuestros actuales rituales de la praxis. ¿Qué nos deja en el fondo, en el subsuelo, en el sótano, o en el techo, la modernidad en cuanto a la necesidad de pertenencia última a un "algo"?

Por esta complicación de la vida teórica con la vida práctica, la filosofía no puede confundirse ni agotarse en una pura función cien- 
tífica o contemplativa, para el homo viator; y, más bien, debe entenderse como el modo egregio en que la existencia del hombre se abre paso hacia la conquista de su fin, pues inclusive en el orden puramente teórico, es una realización humana, intelectual, la que acontece por el conocimiento. La filosofía, así, es el saber que, por conocer el fin, se desdobla en ciencia práctica para fundar el derecho y el deber, como obligaciones de la conducta (Casas 1967 233).

La inauguración de esta figura del viajero en el texto de Casas habilita una movilidad ontoepistémica muy interesante para pensar las categorías de "religo" y de "mundaneidad". En un tránsito finito, acotado, explorable en la medida de una vida humana, en un cuerpo que enferma y perece, podemos repensar la categoría de padecimiento como una arista fundamental de la relación que nos mantiene ligados tanto al mundo como a las otras personas. Y no solo en lo concerniente al ser, sino también en relación con las formas de establecer vínculos de conocimiento, en los que la inteligibilidad es puesta también en juego. En este sentido, el rumbo que el autor sostiene soslaya el planteo benjaminiano que podemos visualizar en El Narrador (1999): la experiencia del viajero como posibilidad de contar la vida, en tanto conocimiento "válido" bajo la forma del saber-consejo. Este lazo propicia el análisis de la mixtura entre este homo viator y el personaje principal de $E l L a$ berinto, en el que Casas ensaya mediante otro formato de escritura esta misma figura del viajante, del homo viator que no deja de ser, también, el homo faber del Renacimiento.

\section{El Laberinto casiano como apreciación contemporánea}

En el escrito casiano El Laberinto, que todavía permanece inédito dentro de su archivo, el personaje principal es nombrado "Carlos" y toda su historia transita un recorrido como viajante. Entre anécdotas, conflictos y amores, se narra la tensión entre la mundanidad de un cuerpo físico en el cual habita, con sus placeres y sus pecados, y un sentimiento de falta que pareciera confirmar que hay "algo" ahí en el fondo que reclama sin apuro por él. Cabe decir que el nombre completo de la obra es El Laberinto. Cuento nivolado en varios sueños y dos pequeñas vigilias, y que, en primer lugar, vigilia y sueños remiten a una idea de ininteligibilidad, a saber: una imposibilidad de conocer de 
manera certera el ámbito en que se despliegan estos momentos, ubicándolos en transiciones difusas que, si bien están subtituladas dentro de la obra, se entrelazan creando situaciones inesperadas en lo que podríamos considerar un "orden real" de los acontecimientos.

Y, en un estadio anterior a pensar la imbricación entre ambos conceptos, hay un sujeto que es quien vive estas instancias. Esta vida, que en sí misma se refiere particularmente a la de Carlos, se articula en una duplicidad problemática: lo irreal y lo real. En primera medida, se podría pensar que la vigilia corresponde a lo real y los sueños a lo irreal, pero Casas no lo separa tajantemente de esa manera: hay algo en el ámbito de la imaginación ensoñada que ventila, cual porosidad, cuestiones ligadas al mundo real, mientras que la vigilia puede representar acontecimientos con cierto grado de irrealidad. Por ejemplo, el sentimiento de multiplicidad que experimenta una persona, ese dislocamiento de sí mismo, esa efervescencia plurifacética que en apariencia delimita el ser como complejidad irresoluble, pero que en el fondo no sino mostración de diversas formas de una misma unidad fundante. Esta unidad forma parte constituyente de la posibilidad de religar-se.

Realidad e irrealidad en una vida humana, así como los estadios de vigilia y sueño, involucran un salto trascendental hacia un sustrato que aúna la diferencia en lo que podríamos llamar una "síntesis". Sistema de pares contrapuestos, en los que también se halla la distinción interna al concepto de persona entre la carne y la esencia. La carne, si la pensamos en términos cartesianos como res extensa, ocupa un lugar en el espacio, pero además existe en el mundo, en clave heideggeriana. Ella está lanzada hacia la muerte y, hacia algo mucho más temible que la condición de materia perecedera: hacia el olvido. En relación a esto, la huida, que se deja ver desde el comienzo de la historia y que pervive hasta resurgir en el final, es un recurso no solo literario sino también teorético: el tiempo finito que recubre a las personas, que las limita, que condiciona su existir en el mundo, esa misma esencia del ser humano como ente temporal, es una idea clave en la lectura. Esto dado que su desarrollo huidizo es, en parte, lo que da pie al autor a hablar de la muerte.

En este escapar-se del homo viator el olvido se juega de lleno. El mismo protagonista ha de salir de sí, de su casa, de su cotidianidad, para encontrar-se en otro lugar, no solo a él mismo sino a su relación 
con el mundo y sus cosas, así como también con los aspectos divinos. El juego entre la vigilia y el sueño también es fundamental para recuperar estos sentidos, ya que el grueso ficcional se da en este momento en el que no se termina de comprender si se trata de una alucinación, de una ensoñación o de un estado de realidad más allá de los alcances de una racionalidad pura. ¿Qué lugar ocupa el religo en la interconexión realidad-irrealidad si pensamos un mundo con otros?

Este espacio aparentemente de sinsentido que sea crea en la obra, lejos de perder toda credibilidad por su carácter fantástico, nos sitúa en la incomodidad de pensar los límites de lo real y en las posibilidades fácticas de esta huida que se presenta en orden invertido a la lectura de Ser y Tiempo (1997). En este cuento, la huida no es para perderse en el uno que nos absorbe en su masa desidentificatoria, sino que aquí es un ir hacia la muerte, en su soledad más íntima, y hacia el olvido, para retomar una conexión primigenia con el origen de todo. Perderse él, separar su carne del cuerpo social, abandonarse para encontrar en ese desgarramiento una unidad fundamental en el fondo de los acontecimientos mundanos.

Lo que se presenta en esta historia es una trascendencia como salto sobre lo real y lo irreal, que, en relación con la vigilia y los sueños, es un ir hacia la verdad unitaria, ininteligible pero intuible, y solo captable en el acto de la fe. Esta, como búsqueda de lo absoluto, es el puente que se elige solo a desmedro de la vida profana, de la carne, que es su antípoda: a costa de un amor que lo retiene en el mundo y no lo deja superar esta instancia transitoria en la ida hacia lo superior. Cabe hacer notar que la referencia a "lo superior" responde a cierto paradigma de lo absoluto; sin embargo, nos parece interesante mantener, más que el ordenamiento, el sentido que el religo connota: el de la unión.

Quien muere luchando por algo, dice el texto, aludiendo a una secuencia de cuestiones políticas, muere luchando por lo absoluto. Es decir, que toda lucha hasta en su aspecto mínimo, responde a fines que trascienden el episodio particular en pos de una resolución más abarcadora del fenómeno en su totalidad: es el fin al cual se estaba refiriendo en su Introducción a la Filosofía. En este sentido, incorpora la noción de "mercado de las ideas" como lugar "común" del pensamiento en la superficialidad, el cual no puede ofrecer sino cuestiones unilaterales, incapaces de involucrarse con el todo de manera participativa, 
ni de asumir su perspectiva desde una unidad fundacional. Como es de esperar, tanto absoluto como unidad y verdad son, en última instancia, dios, como lo es también la esencia del hombre individualizada en cuerpos que cargan el signo del pecado. Quien figura de fondo a lo largo de toda la lectura es Tomás de Aquino, a quien Casas dedicó arduo estudio y de quien se sirvió para construir su concepto de "persona", y a este en relación al ser y al tiempo, nociones que también se articulan como meollo de este cuento.

Ahora bien: si nosotros quisiéramos reducir la síntesis realista a sus puntos de partida sistemáticos, a los principios inteligibles que le darían sentido total, ¿cuál sería nuestro punto de partida? Si quisiéramos - como queremos- ver desde dónde se pone en marcha esta arquitectónica del saber, en la cual jugarán, con soltura y precisión, todos los saberes del hombre, sean especulativos o prácticos, sean teológicos o místicos, habría que decir que el pensamiento de Santo Tomás se construye sobre la base de una primerísima realidad: la aprehensión, por la inteligencia humana, del ser inteligible, presente y envuelto en los datos de nuestros sentidos.

Esto es: que la de Santo Tomás es una filosofía de base experiencial, si no podemos llamarla existencial, por la carga de sentido que esta palabra connota en el pensamiento contemporáneo. $\mathrm{Y}$ es de base experiencial, porque hay una serie de hechos de experiencia que se dan, inmediatamente, como cimiento de su estructura (Casas 1967 156-157).

Es notable cómo Casas se sitúa a sí mismo en su época, dejando ver que el existencialismo era una herramienta de análisis que no se dejaba pasar por alto, teniendo en cuenta también que el auge de la fenomenología tuvo también impacto en ese "ser del hombre" que había quebrado el sentido moderno.

Más allá de su postulación de la existencia de dios como idea reguladora, hay una línea problemática respecto del tiempo, en este caso como condición de posibilidad pura a priori de los fenómenos. Al no poder conocer la cosa en sí, lo único que conocemos está ordenado en el espacio-tiempo, sin los cuales no accederíamos a conocimiento alguno. Y cabe notar cómo la temporalidad aquí se articula de manera distinta, ya que no se ubica en respuesta de la pregunta por el ser, 
sino más bien del conocer, donde intervendrá un Heidegger (1997) a retomar esta primera pregunta que ha sido olvidada. El tiempo se articulará particularmente con el concepto de "angustia" que, según Casas (1967), tiene como antecesor a Kierkegaard, otro filósofo del que notamos una influencia contundente en esta obra, aunque no esté mencionado expresamente.

El concepto heideggeriano de tiempo, en su huida y angustia, tiene locación en un dasein, un ser-ahí que, en su misma composición, conlleva una pregunta también por el mundo en el que se encuentra y la forma en que se relaciona con él. En tanto proyecto, este ente intramundano, arrojado a la muerte, puede tratar de existir de forma auténtica teniendo presente, como resorte motor, esta posibilidad última de su existencia. En el caso de esta obra, se presenta la particularidad de que este ser para la muerte, que en Heidegger es tan significativo, vira su sentido a un ser para la muerte que se reencuentra en dios, lo cual implica una dislocación del sentido que podríamos leer en Ser y Tiempo (1997). Sin embargo, Casas recupera esta base angustiosa para establecer su propia estructura de la huida a través de un personaje de ficción, en un ir hacia dios como aquello que todo lo contiene en última instancia.

En lo que se dijo acerca del temor metodológico que invoca el concepto de dios, Casas recurre a la sentencia nietzscheana - en una mención a Buber- para advertir que quizá no sea que haya muerto, sino que más bien nosotros le cerramos el paso. Esta atribución de sentido le sirve para repensar el quiebre de un abismo, en este caso plausible de ser saltado por la reconexión con lo absoluto, que puede no dejar de ser, de todos modos, moral ascética.

La memoria, a su vez, ya es, de manera incipiente, una temática que en los periodos de posguerra encontrará su auge. Y, si bien no hay como tal un conflicto bélico en la historia de Casas, la misma tiñe de violencia la Casa de Gobierno, en una narrativa que asociamos a la intervención de la ciudad argentina de Córdoba, entre 1943 y 1946, parte de los años en los cuales estaba trabajando efectivamente en la Biblioteca Jorge A. Coll. También notamos que la obra se nutre de un halito existencialista, en el que la elección enarbola su potencia, única instancia en que la carne puede retornar a dios en esta vida: elegir la fe. Esto es lo que elige Carlos en última instancia, siendo lo que sig- 
nifica su huida hacia el encuentro. La configuración de este recorrido conceptual deja en evidencia que el sistema de relaciones es cerrado, decantando todo en la figura de dios.

\section{Conclusiones}

La necesidad de recuperar autores como Manuel Gonzalo Casas radica en que su obra sigue hablándonos, permitiéndonos pensar aspectos de lo humano tan dejados de lado, como el aspecto religioso. Más allá de la institucionalidad, resulta importante pensar cuáles son las condiciones vinculares por las cuales lo humano se mantiene, entendiendo que esto se encuentra a la base, inclusive, de las formas contractuales: hay una noción de ser jugándose en el fondo, y no solo de ser individual sino de ser con otros. En el marco de una historia de las ideas, cobra relevancia porque también nos devuelve a una problemática que nunca dejó de ser tal, pero que, sin embargo, ha estado pasando inadvertida por los grandes temas de investigación actuales.

La religiosidad, entonces, entendida como esta instancia fundamental de lo común, contiene el carácter de lo humano en su seno. En sí misma, ya carga con una idea de unidad, en tanto que hay que re-unirse en aquella primera instancia absoluta, por lo cual pareciera que involucra desde su origen una necesidad sustancial a ser develada. Si bien esto puede ser negado o cuestionado, lo interesante es pensar la experiencia del hombre que hace sentir esa "falta", que pretende encontrar ese fundamento. Y esto es lo peculiar de Casas: lo que en un tratado de filosofía o una clase abierta en la universidad pública puede sonar dogmático, ideológico, fanatizado, entretejido en una novela puede descansar su posición vertical y dejarse interpelar por una trama que busca la puesta en duda, el juego propio del ensayo.

Los modos mediante los cuales construimos conocimiento y habilitamos la pregunta se tornan, entonces, prioritarios. No solo pensar el tema en cuestión sino a través de qué escritura, de qué lenguaje lo vamos a manifestar. La posibilidad que nos brinda el autor entre su obra filosófica y su literatura es un espacio fértil de diálogo, que nos acerca a una cotidianidad mundana sin necesidad de abandonar el concepto filosófico. Ese homo faber que se fue gestando hasta el auge renacentista, que se consolidó durante toda la modernidad y que devino viator, nunca se descompuso del género que lo sostenía en sus andanzas: 
nunca estuvo solo, en sentido trascendental (si no ontológico). Y este no estar solo, este saberse coetáneo, saber-se en un mundo con otros, condiciona su mismo estar. Inclusive, y esto podríamos pensarlo para otro trabajo, más allá de lo meramente humano: en conexión con lo viviente.

\section{Bibliografía}

Benjamin, Walter. Iluminaciones VI. Madrid: Taurus, 1999.

Buber, Martín. Yo y tú. Buenos Aires: Nueva visión, 1984.

Casas, Manuel Gonzalo. El Laberinto. Cuento nivolado en varios sueños $y$ dos pequeñas vigilias. Contenido inédito en el archivo del autor.

Casas, Manuel Gonzalo. Introducción a la filosofía. Madrid: Gredos, 1967.

Casas, Manuel Gonzalo. Introducción al pensamiento real. Buenos Aires: Editorial Hypatia, 1979.

Casas, Manuel Gonzalo. Santo Tomás y la filosofía, con otros ensayos. San Francisco (Argentina): Libros Meteoro, 1947.

Della Mirandola, Pico. Discurso sobre la dignidad del hombre. Mendoza: Revista de literaturas modernas, 1972.

Hegel, Georg W. F. La ciencia de la lógica. vol. II. Madrid: Abada, 2015.

Heidegger, Martin. Ser y Tiempo. Santiago de Chile: Editorial Universitaria, 1997.

Marx, Karl. Manuscritos de 1844. Economía, política y filosofía. Buenos Aires: Cártago, 1984.

Nietzsche, Friedrich. Genealogía de la moral. Madrid: Alianza, 2005.

Roig, Arturo Andrés. Breve historia intelectual de Mendoza. Mendoza: Ediciones del Terruño, 1966. 